\title{
A LÍNGUA BRASILEIRA DE SINAIS - LIBRAS COMO FATOR DETERMINANTE AO ACESSO DO ALUNO SURDO NO MERCADO DE TRABALHO
}

\section{ARTIGO ORIGINAL}

BORBA, Jocélia Emília' ${ }^{1}$ MELO, Josefa Gomes dos Santos², VIEIRA, Maria Merceis da Silva ${ }^{3}$

BORBA, Jocélia Emília. MELO, Josefa Gomes dos Santos. VIEIRA, Maria Merceis da Silva. A língua Brasileira de sinais - libras como fator determinante ao acesso do aluno surdo no mercado de trabalho. Revista Científica Multidisciplinar Núcleo do Conhecimento. Ano 06, Ed. 06, Vol. 06, pp. 117-128. Junho de 2021. ISSN: 24480959, Link de acesso: https://www.nucleodoconhecimento.com.br/educacao/surdono-mercado, DOI: 10.32749/nucleodoconhecimento.com.br/educacao/surdo-nomercado

\section{RESUMO}

A inserção do surdo no mercado de trabalho é uma temática discutida em âmbito nacional, portanto, este artigo objetiva analisar como a (LIBRAS), Língua Brasileira de Sinais é determinante para o acesso do mesmo no mercado de trabalho. Por meio desta pesquisa procura-se verificar como a formação profissional do sujeito surdo the

1 Doutoranda em Educação; Mestrado em Educação; Pós-graduação em Psicopedagogia, Graduação em Pedagogia.

2 Doutoranda em Educação; Mestrado em Educação; Especialista em Ensino de História. Especialista em Psicopedagogia. Graduação em Ciências Sociais.

3 Mestrado em Educação; Pós graduada em Gestão Escolar e Coordenação Pedagógica; Pós Graduada em Metodologia do Ensino Superior; Pós Graduada em Matemática e Graduação em Matemática.

$\mathrm{RC}: 88292$

Disponível em: https://www.nucleodoconhecimento.com.br/educacao/surdo-no-mercado 
oportunizará a entrada no mundo do trabalho, possibilitando-Ihes assumir dimensões abrangentes, e se reconhecer como sujeito útil a uma sociedade democrática sem discriminação e preconceitos, comprometidos com a formação do cidadão e a transformação social. Essa transformação inicia-se quando a escola está comprometida com a educação e a preparação do sujeito para o mundo globalizado. Em decorrência deste fato, questiona-se por que o número de surdos inseridos no mercado de trabalho é tão pequeno? Faz-se necessário criar grupos de estudos com os educadores para discutir programas de formação educacional que garanta ao surdo a permanência no mercado de trabalho. Este artigo de cunho bibliográfico com embasamento teórico em Bakhtin (2006); Botelho (2002); Brasil (1999); Skliar (1997), dentre outros, possibilita aos especialistas em educação novas maneiras de intervir nas escolas sem estigmatizar ou rotular o aluno. Portanto, conclui-se que a melhor forma para ajudar o educando é mostrar que são capazes de driblar essa deficiência e progredir pessoal e profissionalmente. Enfatizam-se o recurso mobilizador a união de forças entre a família e a escola, o afeto e a reflexão para favorecer o desenvolvimento da autoestima e a responsabilidade para com os demais e o ambiente, metas fundamentais da educação em uma escola comprometida com a formação da identidade surda. Por se tratar de uma temática atual e relevante é importante novos estudos e pesquisas, pois a mesma não se esgota aqui.

Palavras-Chave: Surdez, Formação, Oportunidade, Mercado de trabalho.

\section{INTRODUÇÃO}

Este artigo tem como objetivo analisar como a (LIBRAS), Língua Brasileira de Sinais é determinante para o acesso do surdo ao mercado de trabalho.

A inclusão do surdo no mercado de trabalho é hoje um tema bastante discutido, mostra que a população sente a necessidade de incluir esses indivíduos na sociedade e consequentemente ao mundo do trabalho.

RC: 88292

Disponível em: https://www.nucleodoconhecimento.com.br/educacao/surdo-no-mercado 
A limitação do surdo não o impede de exercer uma profissão, pois thes sobram os demais sentidos que fará suprir a necessidade do inexistente.

No entanto, a inclusão deve acontecer em vários setores sociais e não apenas na sala de aula. Sem dúvida a escola é um fator determinante na vida desse jovem, pois através das atitudes do professor o mesmo constrói com sucesso sua trajetória educacional e profissional.

Nota-se que o surdo por não dominar a língua falada é submetido à exclusão social, ou seja, se ele não domina a linguagem verbal que é a prioridade na comunicação do sujeito ouvinte, neste ambiente o surdo será excluído, pois não haverá diálogo/comunicação.

Percebe-se, por esse ângulo, que ouvintes e surdos têm as mesmas possibilidades para se desenvolver bem, tanto o aspecto cognitivo, quanto o linguístico, deixando claro que ambos são capazes de conquistar um espaço no mundo do trabalho.

O ser humano necessita trabalhar para suprir as suas necessidades básicas, como alimentação, vestuário, lazer, entre outros. É através do fruto colhido pelo suor de um dia exaustivo de trabalho que o homem se sente produtivo, podendo colaborar com o crescimento do país.

Sabe-se, que o surdo por fazer parte de uma minoria linguística, enfrenta um grande desafio no momento da procura pelo emprego, por isso há uma dificuldade maior em ser admitido e continuar por um longo período empregado.

Apesar das Leis 8.122/90 e 8. 213/91, que preveem cotas a serem preenchidas por deficientes auditivos nos setores públicos e ou privados, percebe-se, que o número de surdos inseridos no mercado de trabalho formal ou informal ainda é baixo.

Considera-se, um número mínimo de inserção de trabalhadores surdos no mercado de trabalho, mesmo aqueles que concluíram seus estudos, dominam a Língua de Sinais, possuem uma boa qualificação profissional não consegue fixar-se, porque é RC: 88292

Disponível em: https://www.nucleodoconhecimento.com.br/educacao/surdo-no-mercado 
julgado como deficiente ou incapaz. Estes são alguns dos obstáculos encontrados pelos surdos no momento da admissão. $O$ empregador não recebe esse trabalhador, não the oferece uma oportunidade para analisar o seu trabalho e verificar se ele pode ou não continuar na sua empresa, simplesmente, diz no primeiro momento que ele não se encaixa no perfil da empresa, e, que a mesma não estar preparada para lidar com a sua deficiência, dispensando o candidato, sem que o mesmo possa mostrar suas habilidades.

O interesse pelo tema justifica-se, pela falta de oportunidade que a comunidade surda encontra em pleno século XXI de estar inserido no mercado de trabalho, e realizar suas tarefas com dignidade, mostrando sua capacidade física, mental e intelectual diante de uma sociedade ouvinte.

\section{HISTÓRICO DA EDUCAÇÃO DOS SURDOS NO BRASIL}

Até o século $\mathrm{XV}$, os surdos eram considerados primitivos, não tinham direitos e viviam segregados. No Brasil o atendimento às pessoas com necessidades especiais iniciaram no Império com a criação do Instituto Nacional da Educação dos Surdos INES.

No século XVIII, a educação dos surdos mostra grandes avanços, com a fundação de várias escolas. Além disso, qualitativamente, a educação para os mesmos evolui, com a Língua Brasileira de Sinais, eles aprendem e dominam diversos assuntos, além de exercer diferentes profissões. A Constituição de 1988 define no seu artigo 205, define que:

\footnotetext{
A educação, direito de todos e dever do estado e da família, será promovida e incentivada com a colaboração da sociedade, visando o pleno desenvolvimento da pessoa, seu preparo para o exercício da cidadania e sua qualificação para o trabalho (BRASIL, 1988).
}

Neste sentido, cabe à escola reestruturar-se de modo que atenda à diversidade dos alunos, percebendo cada um em sua individualidade, para que aconteça o

RC: 88292

Disponível em: https://www.nucleodoconhecimento.com.br/educacao/surdo-no-mercado 
crescimento, a autoestima pessoal e posteriormente a sua projeção no mercado de trabalho.

A Convenção de Guatemala, realizada em 1999, promulgada no Brasil por meio do decreto $n^{\circ}$ 3.956/2001, traz a premissa que as pessoas sejam elas deficientes ou não têm os mesmos direitos e define discriminação como:

(...) Toda diferenciação, exclusão ou restrição baseada em deficiência, antecedente de deficiência, consequência de deficiência anterior ou percepção de deficiência presente ou passada, que tenha o efeito ou propósito de impedir ou anular o reconhecimento, gozo ou exercício por parte das pessoas portadoras de deficiência de seus direitos humanos e suas liberdades fundamentais (BRASIL, 1999).

O decreto deixa claro, que deve ser feita uma reinterpretação da educação inclusiva, para poder eliminar as barreiras que impedem o acesso dos surdos a escola, pois é no convívio escolar que o sujeito vai adquirir a formação adequada para que ao término de seus estudos possa ser reconhecido como portador de habilidades e competências para o trabalho. Portanto, as pessoas com deficiência não devem ser impedidas de estudar ou participar de todos os acontecimentos da comunidade onde vivem, mesmo porque impedir uma pessoa de participar ativamente na sociedade é crime, pois cada sujeito nasce livre para ir e vir.

\section{O SURDO E A FORMAÇÃO}

Desde a década de 1990, a política educacional para incluir os sujeitos com deficiência vem se difundindo em todo o mundo. Essa política contempla também a comunidade surda.

O surdo deve adquirir sua formação em escolas regulares de ouvintes, para que a convivência com professores e demais integrantes que fazem parte da comunidade escolar favoreça o seu crescimento pessoal e profissional para que no momento que esse jovem deixe a escola esteja apto para assumir com responsabilidade uma profissão digna.

RC: 88292

Disponível em: https://www.nucleodoconhecimento.com.br/educacao/surdo-no-mercado 
É através do conhecimento linguístico que o ser humano estrutura as atividades do dia a dia por meio das conexões cognitivas realizadas no cérebro. Ou seja, a linguagem possibilita ao sujeito interagir para construir novos conhecimentos.

A linguagem é adquirida com o convívio social, mas não quer dizer que o surdo por não possuir a língua falada, seja excluído da sociedade ou do mundo do trabalho. $\mathrm{O}$ surdo tem direito primordial de frequentar uma escola. Cabe à mesma, adequar-se às necessidades dos diferentes alunos que a frequenta. É importante que o corpo docente seja qualificado para que a aprendizagem aconteça de forma significativa.

A Declaração de Salamanca (1994) afirma que:

O compromisso que a escola deve assumir de educar cada estudante, contemplando a pedagogia da diversidade, pois todos os alunos deverão estar dentro da sala regular, independentemente de sua origem social, etnia ou linguística (BRASIL, 1994).

A inclusão do surdo deve ser vista como um processo dinâmico, onde todos saem ganhando quando o grupo se completa.

Sobre esse contexto Skliar diz:

A língua de sinais constitui o elemento identificatório dos surdos, e o fato de constituir-se em comunidade significa que compartilham e conhecem os usos e normas de uso da mesma língua, já que interagem cotidianamente em um processo comunicativo eficaz e eficiente. Isto é, desenvolveram as competências linguísticas e comunicativa e cognitiva por meio do uso da língua de sinais própria de cada comunidade de surdos (SKLIAR, 1997, p. 141).

Os pais, ao matricularem os filhos surdos em escolas para ouvintes, ficam receosos e com medo dos mesmos não se adaptarem ou sofrer discriminação por parte dos colegas. Outra preocupação é a falta de qualificação dos professores no momento da comunicação.

RC: 88292

Disponível em: https://www.nucleodoconhecimento.com.br/educacao/surdo-no-mercado 
O surdo precisa de uma escola democrática, que atenda as especificidades de cada um individualmente, que seja capaz de inserir a Língua de Sinais para toda a turma, para que o sujeito surdo desenvolva tanto o aspecto cognitivo, quanto o linguístico.

Faz-se necessário, que a escola trabalhe com o sujeito, seja ele surdo ou ouvinte, os aspectos sociais, culturais, raciais, étnicos, religiosos, linguísticos etc., pois certamente formará esse jovem para o mundo, ou seja, o mesmo será capaz de construir seus próprios caminhos. Além de propiciar aos alunos o conhecimento das duas línguas, a portuguesa e a LIBRAS.

\section{SURDO X MERCADO DE TRABALHO}

O primeiro impedimento que o indivíduo surdo enfrenta para ingressar no mercado é não possuir a língua falada, para se comunicar com os ouvintes que desconhecem a Língua de Sinais o que dificultará a comunicação entre ambos.

Os indivíduos não recebem a língua pronta para ser usada; eles penetram na corrente da comunicação verbal, ou melhor, somente quando mergulham nessa corrente é que sua consciência desperta e começa a operar. É apenas no processo de aquisição de uma língua estrangeira que a consciência já constituída - graças à língua materna - se confronta com uma língua toda pronta, que só Ihe resta assimilar. Os sujeitos não "adquirem" sua língua materna; é nela e por meio dela que ocorre o primeiro despertar da consciência. (BAKHTIN, 2006 p. 111).

A linguagem é constituída por meio da interação com o outro, essa interação faz com que o sujeito aumente o seu vocabulário. Daí a necessidade do diálogo entre surdosurdo e surdo e ouvinte, porque quando existe o compartilhamento de ideias abre-se um leque para conhecer e aprender a cultura do outro, e a construção do conhecimento acontece. Da mesma forma, no trabalho o indivíduo seja ele surdo ou não tem que se comunicar e mesmo um não tendo o domínio da língua do outro a convivência os ajudará a fortalecer um vínculo e no final ambos serão contemplados, pois a necessidade da comunicação fará com que um aprenda a língua do outro.

$\mathrm{RC}: 88292$

Disponível em: https://www.nucleodoconhecimento.com.br/educacao/surdo-no-mercado 
“(...) a identificação sociocultural e no qual o modelo pedagógico não seja uma obsessão para corrigir o déficit, mas a continuação de um mecanismo de compensação que os próprios surdos, historicamente, já demonstraram utilizar" (SKLIAR, 1997, p. 140).

A aproximação do surdo com grupos de pessoas surdas e oralizadas o ajudará a construir sua identidade, pois a comunicação é fundamental para ampliação do conhecimento humano.

A diferença linguística não torna o surdo menos capaz que o ouvinte, pelo contrário, é no convívio com as diferenças que percebemos o que cada ser é capaz de fazer.

A Língua Brasileira de Sinais é a língua materna do surdo, e, através dela o indivíduo será capaz de aprender a comunicar-se, o que facilitará sua entrada no mercado de trabalho.

A capacitação profissional é imprescindível, principalmente quando se fala de pessoas com limitações. Significa, porém, que o indivíduo deve ter formação adequada e qualificação para exercer com maestria sua função.

A escola diz preparar o jovem para o mercado de trabalho, mas quando vê o número de desempregados que vivem na linha de pobreza apresentados nos meios de comunicação como rádio e televisão percebem-se, o tamanho da desigualdade que existe no país. Daí o desafio para a sociedade que vive numa realidade de exclusão social, onde não apenas os surdos estão excluídos, entram nesse grupo: os pobres, negros, analfabetos etc.

O estigma e o preconceito fazem parte do nosso mundo mental e atitudinal, tendo em vista que pertencemos a categorias - mulheres, negros, analfabetos, professores, judeus, velhos, repetentes na escola, pós-graduados, estrangeiros - que são recebidas com pouca ou muita ressalva por um grupo determinado (BOTELHO, 2002, p. 26).

Enquanto a sociedade olhar as pessoas com preconceito porque pertencem a uma classe minoritária, a segregação e a exclusão continuarão a existir. $O$ indivíduo deve RC: 88292

Disponível em: https://www.nucleodoconhecimento.com.br/educacao/surdo-no-mercado 
ter liberdade de escolher qual profissão seguir e qual se adapta melhor, independente de cor, raça, sexo, etnia, classificação linguística ou classe social.

"Aprender a falar é aprender a estruturar enunciados, sendo que os enunciados produzidos sempre estão cheios de ecos e lembranças resultantes de outros enunciados já ditos, vinculados à esfera da comunicação verbal" (BAKHTIN, 1997, p. 302).

Nesse contexto, a pessoa surda não precisa se apropriar da fala para se comunicar, muito menos da comunicação verbal, pois a Língua de Sinais é o suficiente para a socialização e comunicação entre os pares.

O surdo é independente, não precisa de outra pessoa para aprender a se comunicar, mesmo sendo minoria, ele sabe os direitos que possui e está em busca de melhores condições de vida, ando buscando o seu espaço no mercado de trabalho. As pessoas são livres para crescer e se desenvolver, portanto, visando esse crescimento o surdo construiu sua Língua de Sinais.

Estudos apontam que a pessoa surda aprende e desenvolve-se melhor quando faz o uso da Língua Brasileira de Sinais (LIBRAS) como sua primeira língua.

“(...) um ser humano não é desprovido de mente ou mentalmente deficiente sem uma língua, porém está gravemente restrito no alcance de seus pensamentos, confinado, de fato, a um mundo imediato, pequeno" (SACKS, 1998, p. 52).

A função do educador não será precisamente o de ensinar a ler, mas a de criar condições para que o educando, surdo ou não, consiga alcançar sua própria aprendizagem. Ou seja, a Língua de Sinais é determinante para que o surdo possa ser encaminhado ao mercado de trabalho, pois para essa classe é sua primeira língua e o português sua segunda língua, o que deixa claro que o mesmo dominando a sua língua materna está apto para sua colocação no mercado de trabalho.

RC: 88292

Disponível em: https://www.nucleodoconhecimento.com.br/educacao/surdo-no-mercado 


\section{A ACESSIBILIDADE NO MERCADO DE TRABALHO}

Antes do acesso ao primeiro emprego, o sujeito é submetido a uma entrevista, o que determinará se está apto ou não a ocupar uma vaga no mercado de trabalho. surdo enfrenta logo neste primeiro contato uma dificuldade, que é não possuir a língua falada, mas ele pode apresentar-se com um intérprete para que o mesmo traduza a língua de sinais para a língua oral. Cumprindo essas exigências legais nada mais impedirá esse jovem de entrar no mercado de trabalho, possibilitando ao mesmo exercer plenamente sua cidadania percebendo-se útil à sociedade da qual faz parte. Mas, existe um preconceito enraizado na sociedade, o que diminui as chances de uma pessoa com deficiência ingressar no mercado de trabalho.

Um dos problemas é relativo à resistência dos empregadores em contratar pessoas surdas. Elas sofrem o preconceito e, muitas vezes, veem negadas as oportunidades de mostrar suas capacidades e talentos. Quando conseguem um emprego, sentem dificuldades para construir relações interpessoais e compreender a própria dinâmica do espaço laboral (MARIN; GOÉS, 2006 p. 236).

Portanto, é preciso que a lei de cotas seja cumprida na prática. E diante do contexto, a empresa contrata o intérprete que é o profissional conhecedor da Língua de Sinais, para que os jovens surdos possam entender o que está sendo abordado e intervir no diálogo se achar conveniente; assim a interpretação ocorre com a presença deste profissional que de maneira clara e precisa, repassa todo o conteúdo através de sinais e o surdo participará ativamente da conversa.

A Lei 9394/96 deixa claro em seus art. 39 e 59, incisos I e IV, que:

Art. 39 - A educação profissional integrada às diferentes formas de educação, ao trabalho, à ciência e à tecnologia, conduz ao permanente desenvolvimento de aptidões para a vida produtiva Art. 59 - Os sistemas de ensino assegurarão aos educandos com necessidades especiais. I - Currículos, métodos, técnicas, recursos educativos e organização específicos para atender às suas necessidades; IV - educação especial para o trabalho, visando a sua efetiva integração na vida em sociedade, inclusive condições adequadas para os que não revelarem capacidade de inserção no trabalho competitivo, mediante articulação com órgãos oficiais afins,

RC: 88292

Disponível em: https://www.nucleodoconhecimento.com.br/educacao/surdo-no-mercado 
bem como para aqueles que apresentam uma habilidade superior nas áreas artísticas, intelectual ou psicomotora (BRASIL, 1996).

A sociedade, deve oferecer condições para que o surdo possa competir em igualdade com os demais trabalhadores, para que isso ocorra é preciso que programas de formação profissional sejam elaborados de forma que atenda as especificidades de todos, para que não haja discriminação perante uma categoria. A partir desses programas ficará claro onde cada indivíduo tem mais habilidade para produzir, fazendo com que o mesmo chegue à conclusão de qual profissão ele exercerá com mais segurança.

Sabe-se, que o surdo por ter a limitação de não ouvir não pode assumir cargos que dependam exclusivamente da audição como recepcionista, telefonista etc., mas sem dúvida ocupará com brilhantismo serviços nas áreas artísticas, intelectual, tecnológica e psicomotora.

Chega de segregação, de querer menosprezar uma pessoa sem conhecer o que ela pode oferecer a sociedade pelo simples fato de possuir uma especificidade que é inerente à todos os seres humanos, independente de possuir deficiência ou não.

\section{CONSIDERAÇÕES FINAIS}

Compreende-se, a importância da escola, como um espaço de atuação e de forças que contribui na luta contra as discriminações sociais, raciais e linguísticas. Uma escola comprometida em combater as desigualdades pode direcionar um trabalho de conscientização, onde todos em suas diferenças participam do processo de transformação. Tal escola, comprometida com o futuro dos seus jovens terá função facilitadora, para os mesmos conquistarem as mais amplas condições de contribuir de forma ativa no mercado de trabalho.

Revela-se, que para formar indivíduos autônomos, criativos e críticos requer o desenvolvimento de ações articuladas pelas escolas ao longo do seu processo pedagógico, na elaboração do planejamento flexível, que atenda cada um respeitando

RC: 88292

Disponível em: https://www.nucleodoconhecimento.com.br/educacao/surdo-no-mercado 
as suas limitações e especificidades, garantindo-Ihes autonomia no fazer. Para isso, uma relação de cumplicidade entre professor-aluno é fundamental, para que o mesmo se sinta preparado para atuar na sociedade e no mercado de trabalho.

Percebe-se, que a cada dia o modelo de educação brasileira busca inserir seus alunos em uma sociedade igualitária. Para que isso ocorra é necessário que surdos e ouvintes ocupem o mesmo espaço no contexto escolar, fazendo com que todos participem ativamente, para a edificação de uma educação justa e de equidade social.

Enfim, observou-se, que para melhorar o acesso do surdo ao mercado de trabalho é preciso unir forças de todos que fazem parte do processo ensino e aprendizagem; além da família, e, claro das instituições envolvidas com as políticas públicas, para que o surdo tenha mais oportunidades de trabalho, promovendo assim uma sociedade mais justa, onde uma deficiência seja apenas uma condição física e não um divisor para determinar quem é capaz ou não de contribuir com o crescimento do país.

Verificou-se, que o acesso do surdo ao mercado de trabalho é um tema de grande relevância e estimulante, portanto, merece ser alvo de novas investigações científicas no campo acadêmico, tanto por estudantes como por outros profissionais que tenham interesse pela temática, pois a mesma é inesgotável.

\section{REFERÊNCIAS}

BAKHTIN, M. Marxismo e filosofia da linguagem. 12. ed. São Paulo: Hucitec, 2006.

BAKHTIN, M. Os gêneros do discurso. In: BAKHTIN, M. Estética da criação verbal. Trad. de Maria Hermantina Galvão Gomes Pereira. São Paulo: Martins Fontes, 1997.

BOTELHO, Paula. Linguagem e Letramento na Educação dos Surdos: ideologias e práticas pedagógicas. Belo Horizonte: Autêntica 2002.

BRASIL. Lei de Diretrizes e Bases da Educação nacional. Lei no 9394/96. Brasília DF.1996.

RC: 88292

Disponível em: https://www.nucleodoconhecimento.com.br/educacao/surdo-no-mercado 
BRASIL. Assembleia Nacional Constituinte. Constituição da República Federativa do Brasil. Brasília, DF: Senado Federal, 1988.

DECLARAÇÃO da Guatemala. Convenção Internacional para a eliminação de todas as formas de discriminação contra as pessoas portadoras de deficiência. Guatemala, 1999.

DECLARAÇÃO de Salamanca: Sobre princípios, políticas e práticas na área das necessidades educativas especiais. Salamanca - Espanha, 1994.

DIZEU, Liliane Correia Toscano de Brito; COPARALI, Sueli Aparecida. A língua de sinais constituindo o surdo como sujeito. Educação e Sociedade. Vol. 26; 2006.

MARIN, C. R. GOES C. R. A experiência de pessoas surdas em esferas de atividade do cotidiano. Vol 26. Campinas-SP: Cad. Cedes, 2006.

SACKS, O. Vendo vozes: uma viagem ao mundo dos surdos. São Paulo: Cia das Letras, 1998.

SKLIAR, Carlos (org.). Educação \& Exclusão: abordagens socioantropológicas em educação especial. Porto Alegre: Mediação 1997.

SKLIAR. A Surdez: um olhar sobre as diferenças. Porto Alegre: Mediação, 1998. A invenção e a exclusão da alteridade "deficiente" a partir dos significados da normalidade. Educação e Realidade. Porto Alegre. V.24 n.2 jul./dez. 1997.

Enviado: Março, 2021.

Aprovado: Junho, 2021.

RC: 88292

Disponível em: https://www.nucleodoconhecimento.com.br/educacao/surdo-no-mercado 